\title{
A Case Report of Rare Metastatic Breast Cancer with Oesophageal Metastasis
}

\author{
Nayab Mustansar* \\ Consultant Nuclear Physician, Pakistan \\ *Corresponding author: Nayab Mustansar, Consultant Nuclear Physician, Pakistan
}

\begin{tabular}{|c|c|}
\hline ARTICLE INFO & ABSTRACT \\
\hline Received: 豐 August 26, 2019 & Abbreviations: CT: ChestComputed Topography; EGD: Esophago-Gastro-Duodenoscopy; \\
\hline Published: 幽 September 04, 2019 & PET-CT: Positron Emission Tomography-Computed Tomography \\
\hline
\end{tabular}

Citation: Nayab Mustansar. A Case Report of Rare Metastatic Breast Cancer with Oesophageal Metastasis. Biomed J Sci \& Tech Res 21(1)-2019. BJSTR. MS.ID.003551.

\section{Introduction}

It is very rare to have esophageal metastasis with Breast carcinoma [1]. Carcinoma Breast is the commonest cancer in females. It commonly metastasizes to bone, liver, brain and Liver. Rarely metastasize to Oesophagus [2]. It is very uncommon to diagnose esophageal stricture due to breast cancer metastasis; most cases are evident after autopsy or surgery [3]. Breast cancer presenting with dysphagia as the first manifestation is rarely reported, as esophageal metastasis typically occurs a long time after diagnosis and treatment of the primary breast tumor [4].

\section{Case Report}

\section{History}

A 60-year-old woman was admitted due to

a) Progressive Dysphagia over the course of 2 months

b) The patient had lost $10 \mathrm{~kg}$

c) No History of diarrhea

d) No Hematochezia

e) No Abdominal Distension

f) The patient had no Family history of Malignancy

g) No other active Complaint

\section{Physical Examination}

A physical examination found no abnormalities.

\section{Investigations}

Following investigations were done, as shown in Figures 1\& 2:

a) A barium swallows

b) Identified a stricture in the center of the esophagus

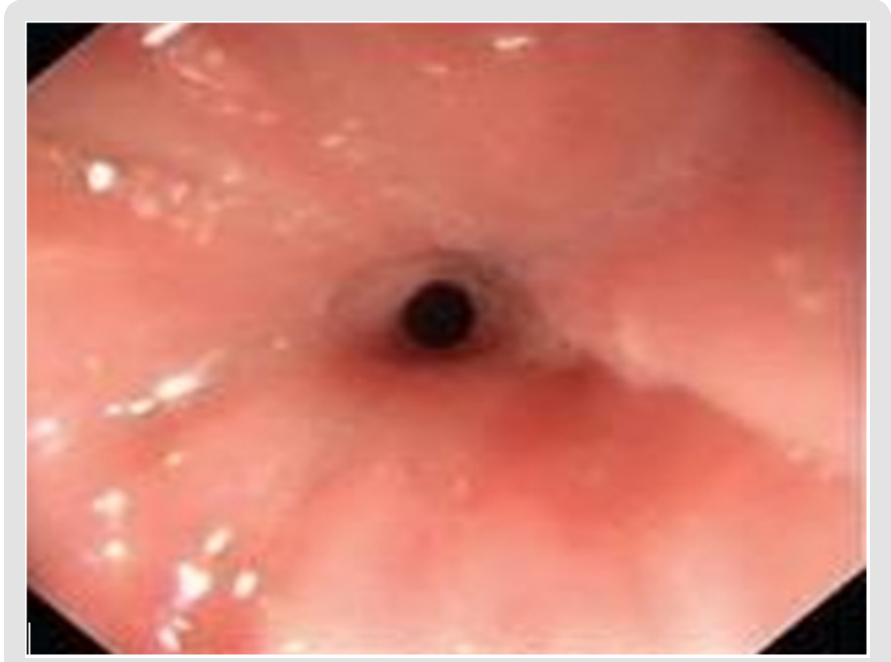

Figure 1. 


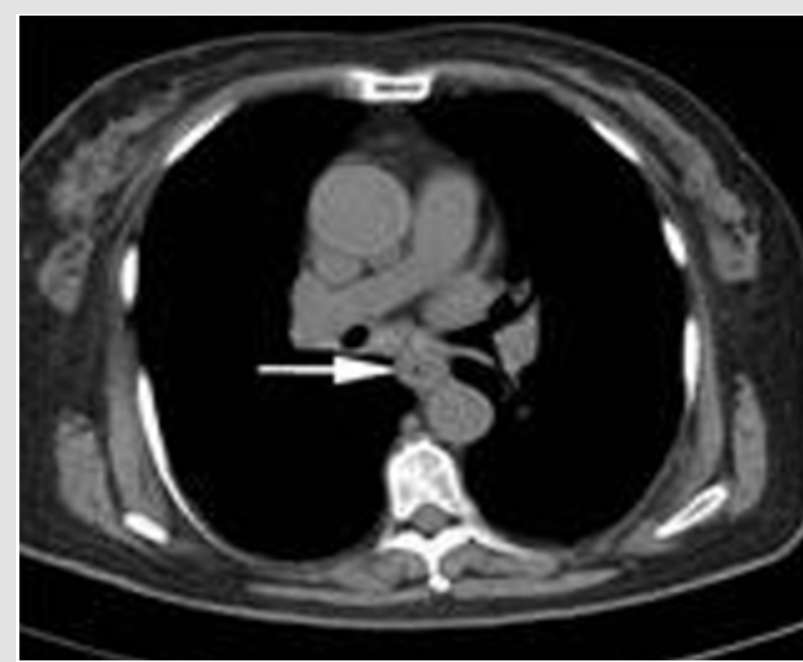

Figure 2.

Chest Computed Tomography (CT): Revealed a thickened esophageal wall at the site of the stricture and a dilated upper esophagus. There were multiple enlarged lymph nodes on the bilateral sub axillary, hilar, and mediastinal regions.

An Esophago-Gastro-Duodenoscopy (EGD): Showed the esophageal lumen stenosis and normal mucosa. Using an endoscopic ultrasound (EUS), the thickness of the esophageal wall was found to be about $1.4 \mathrm{~cm}$, and its structure was classified as abnormal.

The Ultrasound of the Breast and Axillary Lymph Node: Found that there was a hypoechoic nodule of $1.2 \times 0.8 \mathrm{~cm}$ at the 12 o'clock direction from the right nipple. The structure of the right axillary lymph nodes had been destroyed.

Positron Emission Tomography-Computed Tomography (PET-CT): Demonstrated that the mid-esophagus wall was thickened with a maximum of standard uptake value (SUV) of 4.8. There were irregular nodules above the right nipple (SUV 3.7), and there were enlarged lymph nodes in the right axillary area, which could not exclude malignant tumor metastasis. Histopathology by endoscopic ultrasound-guided fine needle biopsy (EUSFNB) indicated that several allotype spindle cells had infiltrated into the fibrous and smooth muscle tissues, some of which had undergone plasmacytoid changes. The tumors were diagnosed as poorly differentiated carcinoma after combining these data with immunohistochemical analyses.

Immunohistochemical: Results were as follows: AE1/AE3 (+), CD138 (-), Ki-67 (index 40\%), S-100 (-), SMA (-), P53 (-), ER $(80 \%)$.

Excision Biopsy of the Nodule: Located in the right breast revealed breast invasive ductal carcinoma (moderately to well differentiated, the second grade).

Immunohistochemistry: ER (10\%), PR (-), Her-2 (-), EGFR $(-)$, CD10 (-), CK5/6 (-), ECadherin (+), CgA, Ki-67 (20\%), P120 (membrane + ), P63 (-), P53 (-), Syn (-).

\section{Discussion}

Esophageal involvement in breast cancer mostly occurs in postmenopausal women. The most common clinical manifestation is dysphagia, accompanied by weight loss, anorexia, vocal dysfunction, and so on. Patients may not experience dysphagia until $7.1 \pm 4.2$ years after being diagnosed and treated for breast cancer [4]. Metastatic lesions are typically located in the middle or distal thirds of the esophagus, which may be related to lymph node metastasis [2]. Our patient was a postmenopausal woman with an initial presentation of dysphagia. An upper digestive tract radiograph, CT scan, and endoscopy all suggested stricture in the mid-esophagus. The mechanism of esophageal involvement in breast cancer has been controversial. Tumor cells may metastasize to periesophageal lymph nodes through intra-mammary lymphatic channels, leading to esophageal obstruction. In some cases, metastasis may cause intramural tumor deposition deeper in the mucosal layer. Therefore, endoscopic analysis can show normal esophageal mucosa in many patients with esophageal stricture [5]. In our case, EUS revealed thickening of the esophagus wall without enlargement of the periesophageal lymph nodes. Postoperative pathological results revealed no metastasis to the paraoesophageal lymph nodes. Thus, in this case, intramural metastasis caused the stricture.

Diagnosis of an esophageal stricture due to breast cancer is difficult, as differentiating primary esophageal tumors, benign esophageal strictures, and mediastinal carcinomatosis is not trivial when the lesion is in the submucosa and is surrounded by a normal mucosa. Endoscopic biopsies are usually negative for submucosal lesions. Metastatic esophageal cancer was highly suspected in our patient, and tissue pathology analyses obtained by EUSFNB classified the lesion as poorly differentiated carcinoma, confirming the malignant diagnosis. Endoscopic mucosal resection (EMR) is another method for safely collecting tissue for histological diagnosis. EMR has been used to diagnose breast cancer metastasis to the esophagus in a patient presenting with esophageal stricture [7]. Because esophageal metastasis from breast cancer is rare, and patients are asymptomatic for a long time, the prognosis is difficult to predict. It has been reported that treatment by esophagectomy has the best outcome. Radiotherapy, chemotherapy, and hormone therapy are also effective treatments. Our patient did not undergo modified radical mastectomy/axillary lymphadenectomy and received TAC chemotherapy and hormone therapy as definitive treatment. She was expected to have a good prognosis.

\section{References}

1. Haney JC, D Amico TA (2004) Transhiatal esophagogastrectomy for an isolated ovarian cancer metastasis to the esophagus. J Thorac Cardiovasc Surg 127(6): 1835-1836.

2. Rampado S, Ruol A, Guido M (2007) Mediastinal carcinosis involving the esophagus in breast cancer: the "breast-esophagus" syndrome: report on 25 cases and guidelines for diagnosis and treatment. Ann Surg 246(2): 316-322.

3. Varanasi RV, Saltzman JR, Krims P (1995) Breast carcinoma metastatic to the esophagus: clinicopathological and management features of four cases, and literature review. Am J Gastroenterol 90(9): 1495-1499. 
4. Anderson MF, Harell GS (1980) Secondary esophageal tumors. AJR Am J Roentgenol 135(6): 1243-1246.

5. Suzuki R, Singh H, Rami Reddy S (2013) Endoscopic ultrasound-guided fine needle aspiration for smooth benign appearing esophageal stricture due to metastatic breast cancer. Endosc Ultrasound 2(1): 35-37.

ISSN: 2574-1241

DOI: 10.26717/BJSTR.2019.21.003551

Nayab Mustansar. Biomed J Sci \& Tech Res

(c) (P) This work is licensed under Creative Commons Attribution 4.0 License

Submission Link: https://biomedres.us/submit-manuscript.php
6. Sobel JM, Lai R, Mallery S (2005) The utility of EUS-guided FNA in the diagnosis of metastatic breast cancer to the esophagus and the mediastinum. Gastrointest Endosc 61(3): 416-420.

7. Sunada F, Yamamoto H, Kita H (2005) A case of esophageal stricture due to metastatic breast cancer diagnosed by endoscopic mucosal resection. Jpn J Clin Oncol 35: 483-486.

$\begin{array}{ll}\text { BIOMEDICAL } & \text { Assets of Publishing with us } \\ \text { RESEARCHES } & \text { - Global archiving of articles } \\ & \text { - Immediate, unrestricted online access } \\ \end{array}$

